\title{
Drafting a fuzzy TOPSIS-multi-objective approach for a sustainable supplier selection
}

\author{
Ahmed Mohammed ${ }^{1}$, Misha Filip ${ }^{2}$ \\ ${ }^{1}$ School of Engineering, Cardiff University \\ Cardiff, UK \\ Mohammeda9@cardiff.ac.uk
}

\author{
Rossi Setchi ${ }^{1}$ and Xiaodong $\mathrm{Li}^{3}$ \\ ${ }^{3}$ Department of Engineering Design and Mathematics \\ University of West England \\ Bristol, UK \\ ${ }^{2}$ School of Engineering, University of Portsmouth \\ Portsmouth, UK
}

\begin{abstract}
In spite of the increasing awareness apparent in the literature regarding the selection of sustainable suppliers, there are limitations in incorporating the sustainable performance in terms of traditional, environmental and social aspects in supplier selection and order allocation. Thus, an integrated fuzzy TOPSIS-multi objective optimization (MOO) approach was developed to integrate sustainable performance into the evaluation and ranking of two-stage supplier selection in conjunction with the optimal order allocation in a meat supply chain. The sustainable performance of suppliers based on traditional, environmental and social criteria was evaluated by using fuzzy TOPSIS. The optimal quantity of products to be ordered from each supplier was determined through a development of multi-objective optimization model. To obtain a set of Pareto solutions derived from the multiobjective optimization model, the LP-metrics method was employed. The quality of the obtained Pareto solutions was evaluated using the global criterion approach aiming to select the final Pareto solution. To examine the applicability of the developed integrated fuzzy TOPSIS-multi-objective approach, a case study was applied.
\end{abstract}

Keywords-Supplier selection; Sustainability; Meat supply chain; Fuzzy TOPSIS; multi-objective

\section{INTRODUCTION}

Supply chain management includes all the operations related to the flow of merchandises and services from the source point to the usage point [1]. Boran [2] argued that supply chain management aims at decreasing production risks and production costs, increasing total income, managing inventory levels, fulfilling customer demands and business activities and maintaining a successful business competitiveness. Supplier selection and order allocation is a main key factor in implementing a robust supply chain management [3]. This is based on the fact that firms depend more on suppliers to obtain a costeffective product quality. Furthermore, purchasing activity is one of the main task for enterprises since its costs represents more than $50 \%$ of all enterprises internal costs [4]. Supplier selection and order allocation can be defined as the activity of selecting the best suppliers and allocating the optimal quantity of products to be purchased among them for obtaining a stabilized environment of competitiveness [5].

A sustainable supply chain management is a new pattern that has been emerging recently in industries and enterprises [6]. It makes a significant influence on supply chain performance in the economic, environmental and social aspects. This new pattern increases the challenges for a decision maker in selecting the sustainable suppliers in which takin into account traditional (e.g., economic), environmental and social aspects. Arguably, sustainability of a supply chain depends mainly on the purchasing strategy of the supply chain partners.

Food sector is increasingly gaining an importance in today's global business particularly as the global demand of food may be doubled by 2050. Food supply chains have some unique characteristics such as the freshness and safety of products e.g. vegetables and processed food products [7]. This adds a new significant criterion to decision makers to consider in selecting the best supplier.

Considering the complex multi-criteria nature of supplier selection and order allocation problem, multicriteria decision making (MCDM) usage has become a fruitful in this field of research. These techniques lead decision makers to thoroughly obtain compromised solutions among conflicting criteria when evaluating and selecting suppliers. Bottani [8] used fuzzy analytical hierarchic process (AHP) to solve a supplier selection problem in an e-procurement environment. Chen [9] used The Technique for Order of Preference by Similarity to Ideal Solution (TOPSIS) for proposing an approach used for handling supplier selection problem. Roshandel [10] employed fuzzy hierarchical TOPSIS for ranking suppliers in detergent production sector. Junior [11] compared the performance of fuzzy TOPSIS and fuzzy AHP in evaluating and ranking suppliers. Akman [12] suggested a two-step supplier assessment framework to evaluate green supplier. Kannan [13] investigated a green supplier selection problem in a plastic enterprise using a fuzzy axiomatic design approach. Hsu [14] employed a decision-making trial and evaluation laboratory approach to assign influential criteria of carbon management in green supply chains for improving the overall 
performance of suppliers. Govindan [15] solved a supplier selection problem in a food supply chain using a hybrid approach that includes the revised Simos procedure, PROMETHEE methods for constructing a group compromise ranking, and robustness analysis.

This research presents a development of an integrated approach for solving a two-stage supplier selection and order allocation problem in a meat supply chain considering traditional, environmental and social aspects in addition to the travel time which is a main key factor for food quality. Supply chain managers may utilize the developed approach to rank the suppliers with respect to several sustainable criteria.

\section{THE INTEGRATED FUZZY TOPSIS-MOO APPROACH}

This work aims at solving a sustainable supplier selection and order allocation problem for a meat supply chain consists of sets of farms, abattoirs and retailers through a development of an integrated fuzzy TOPSISmulti-objective optimization approach. Fig.1 shows three sets of criteria used for evaluating the suppliers. Fuzzy TOPSIS was used for evaluating and ranking suppliers based on the criteria shown in Fig. 1. A multi-objective model was developed for allocating the optimal quantity of livestock and meat packets to be purchased from each livestock and meat packets suppliers, respectively. Finally, global criterion approach was used to help the decision makers in determining the final Pareto solution derived from solving the multi-objective optimization problem.

\section{A. Fuzzy TOPSIS}

In this work, Fuzzy TOPSIS was used for ranking suppliers based on traditional, green and social criteria. Decision makers need to evaluate each potential supplier with respect to each criterion in each of the three sets of criteria (e.g. traditional, green and social). Fuzzy TOPSIS was implemented based on the following steps [16]:

\section{Notations}

i set of suppliers

j set criteria

$\mathrm{k} \quad$ set decision makers

$\mathrm{w}_{\mathrm{j}}$ importance of criterion $\mathrm{i}$

$\mathrm{w}_{\mathrm{ij}}$ ranking of supplier $\mathrm{i}$ with respect to criterion $\mathrm{j}$

$\left(l_{j 1}, m_{j 2}, u_{j 3}\right)$ lower, middle and upper values in the triangular fuzzy numbers referring to the importance of criterion $\mathrm{j}$

$\left(\mathrm{l}_{\mathrm{ij} 1}, \mathrm{~m}_{\mathrm{ij} 2}, \mathrm{u}_{\mathrm{ij} 3}\right)$ lower, middle and upper values in the triangular fuzzy numbers referring to the ranking of supplier $\mathrm{i}$ with respect to criterion $\mathrm{j}$

$\mathrm{n}_{\mathrm{ij}} \quad$ normalized triangular fuzzy numbers

M matrix of normalized triangular fuzzy numbers

$\mathrm{r}^{\mathrm{ij}} \quad$ weighted normalized triangular fuzzy numbers

$\mathrm{R}$ matrix consisting of weighted normalized triangular fuzzy numbers

\section{$\mathrm{S}^{+}$positive ideal solution}

$\mathrm{S}^{-}$negative ideal solution distance of supplier $\mathrm{i}$ from the positive ideal solution

$\mathrm{S}^{+}$distance of supplier i from the negative ideal solution S-

CC closeness coefficient

Step 1: The evaluation of criteria/sub-criteria and ranking of suppliers with respect to the criteria are performed. Table I and Table II present the linguistic variables used for evaluating the criteria and ranking the suppliers, respectively [17].

Step 2: linguistic variables shown in Tables I and II were re-presented into the form of triangular fuzzy numbers. By using Eqs. 1 and 2, importance weights of criteria were determined.

$$
\begin{aligned}
& w_{i j}=\frac{1}{K}\left(w_{i j}{ }^{1}, w_{i j}{ }^{2}, \ldots, w_{i j}{ }^{k}\right), \quad w_{i j}=\left(l_{i j 1}, m_{i j 2}, u_{i j 3}\right) \\
& w_{j}=\frac{1}{K}\left(w_{j}{ }^{1}, w_{j}{ }^{2}, \ldots, w_{j}{ }^{k}\right), \quad w_{j}=\left(l_{j 1}, m_{j 2}, u_{j 3}\right)
\end{aligned}
$$

Step 3: the matrix of normalized triangular fuzzy number $(M)$ as obtained as follows:

$$
M=\left\lfloor n_{i j}\right\rfloor_{n x m}
$$

where

$$
\begin{aligned}
& n_{i j}=\left(\frac{l_{i j}}{\sqrt{\sum_{i} u_{i j}^{2}}}, \frac{m_{i j}}{\sqrt{\sum_{i} u_{i j}^{2}}}, \frac{u_{i j}}{\sqrt{\sum_{i} u_{i j}^{2}}}\right), \\
& i=1,2,3, \ldots, m, j=1,2,3, \ldots, n
\end{aligned}
$$

Step 4: the weighted normalized decision matrix $(R)$ is obtained using Eq. 5.

$$
R=\left\lfloor r_{i j}\right\rfloor_{n x m}, i=1,2,3, \ldots, m, j=1,2,3, \ldots, n
$$

Where $r_{i j}$ is obtained using the following equation:

$$
r_{i j}=n_{i j} x w_{j}
$$

Step 5: By using Eqs. 7 and 8, the fuzzy positive and negative ideal solutions are determined.

$$
\begin{aligned}
& S^{+}=\left\{s_{1}^{+}, s_{2}^{+}, \ldots, s_{n}^{+}\right\} \\
& S^{-}=\left\{s_{1}^{-}, s_{2}^{-}, \ldots, s_{n}^{-}\right\}
\end{aligned}
$$

Step 6: By using Eqs. 9 and 10, the distance of each supplier from the positive ideal solution $\left(D_{i}^{+}\right)$and the negative ideal solution $\left(D_{i}^{-}\right)$are calculated.

$$
\begin{gathered}
D_{i}^{+}=\sum_{j \in n} D_{v}\left(r_{i j}, s_{j}^{+}\right) ; \quad i=1,2,3, \ldots, m \\
\mathrm{D}_{i}^{-}=\sum_{j \in n} D_{v}\left(r_{i j}, s_{j}^{-}\right), \quad i=1,2,3, \ldots, m
\end{gathered}
$$

Step 7: By using the values obtained using Eqs. 9 and 10, the closeness coefficient (CC) for each supplier is determined using Eq. 11. The supplier with the highest $\mathrm{CC}$ (varies between 0 and 1) is selected as the best alternative. 


$$
C C=\frac{d_{i}^{-}}{d_{i}^{+}+d_{i}^{-}}
$$

A multi-objective optimization model was developed to solve the order allocation problem for the supply chain under investigation in allocating the quantities of products (e.g., livestock and meat packets) to be ordered from each selected supplier (e.g. farms and abattoirs). The objectives are minimization of the expected costs (F1), environmental impacts (F2) and travel time (F4) and maximization of social impacts (F3).

\section{Sets}

$I$ set of livestock suppliers (farms) $(1 \ldots i \ldots I)$

$J$ set meat packets suppliers (abattoirs) $(1 \ldots j \ldots J)$

$K$ set retailers $(1 \ldots k \ldots K)$

\section{Parameters}

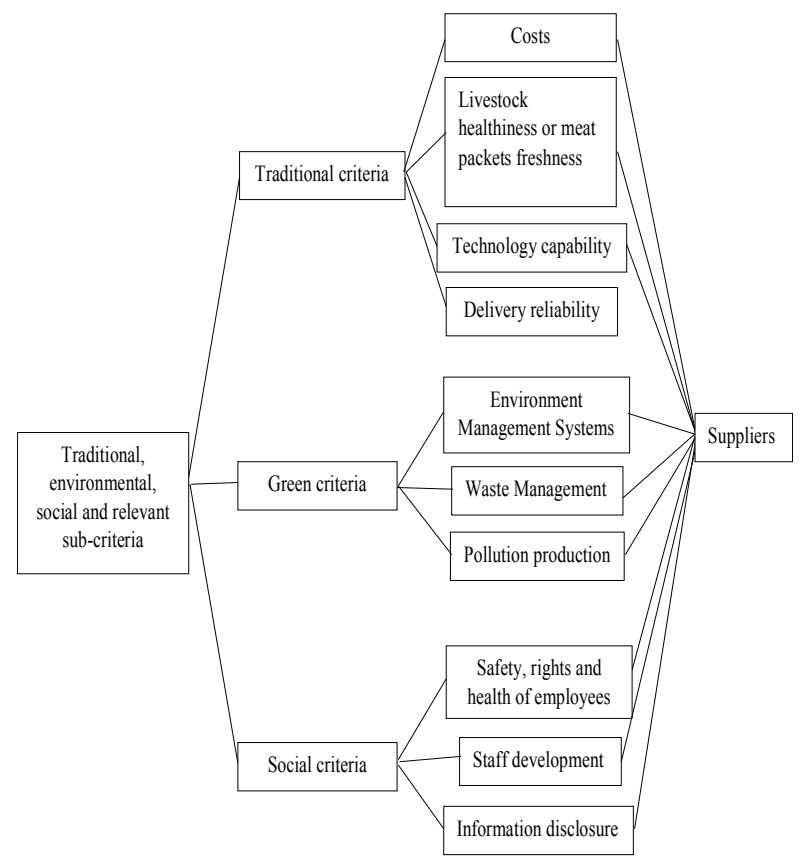

Fig. 1. Sustainable criteria used for evaluating supplier.

TABLE I. LINGUISTIC VARIABLES USED FOR EVALUATING CRITERIA AND SUB-CRITERIA

\begin{tabular}{cc}
\hline Linguistic Variable & Fuzzy number \\
\hline Very Low (VL) & $(0,0,0.1)$ \\
Low $(\mathrm{L})$ & $(0,0.1,0.3)$ \\
Medium (M) & $(0.2,0.4,0.5)$ \\
High $(\mathrm{H})$ & $(0.7,0.9,0.10)$ \\
Very High (VH) & $(0.8,0.10,0.10)$ \\
\hline
\end{tabular}

TABLE II. LINGUISTIC VARIABLES USED FOR RANKING SUPPLIERS

\begin{tabular}{cc}
\hline Linguistic Variable & Fuzzy number \\
\hline Very Low (VL) & $(0,0,1)$ \\
Low (L) & $(0,1,3)$ \\
Medium (M) & $(2,4,5)$ \\
High (H) & $(7,9,10)$ \\
Very High (VH) & $(8,10,10)$ \\
\hline
\end{tabular}

$C_{i}^{p}$ purchasing cost per unit of livestock ordered from supplier $i$

$C_{j}^{p}$ purchasing cost per unit of meat packets ordered from supplier $j$

$C_{i j}^{t} \quad$ unit transportation cost per mile from supplier $i$ to abattoir $j$

$C_{j k}^{t}$ unit transportation cost per mile from supplier $j$ to retailer $k$

$C_{i}^{a}$ administration cost per order of supplier $i$

$C_{j}^{a}$ administration cost per order of supplier $j$

$d_{i k}$ transportation distance of livestock from farm $i \mathrm{t}$ abattoir $k$

$d_{j k}$ transportation distance of meat packets from abattoir $j$ to retailer $k$

$T C$ transportation capacity per lorry

$V \quad$ velocity of lorry

$S_{i} \quad$ maximum supply capacity of supplier $i$

$S_{j} \quad$ maximum supply capacity of supplier $j$

$\mathrm{D}_{j}$ minimum quantity of livestock to be ordered by abattoir $j$

$\mathrm{D}_{k}$ minimum quantity of livestock to be ordered by retailer $k$

$\mathrm{CO}_{2 i j} \quad \mathrm{CO}_{2}$ emission in gram per mile for each lorry travelling from farm $i$ to abattoir $j$

$\mathrm{CO}_{2 j k} \quad \mathrm{CO}_{2}$ emission in gram per mile for each lorry travelling from abattoir $j$ to retailer $k$

\section{Decision variables}

$q_{i j} \quad$ quantity of livestock ordered from farm $i$ to abattoir $j$

$q_{j k}$ quantity of meat packets ordered from abattoir $j$ to retailer $k$

Binary decision variables

$u_{i}=\left\{\begin{array}{c}1: \text { if supplier } i \text { is selected } \\ 0: \text { otherwise }\end{array}\right.$
$v_{j}=\left\{\begin{array}{c}1: \text { if supplier } j \text { is selected } \\ 0: \text { otherwise }\end{array}\right.$

Minimization of expected cost (F1)

This objective function aims at minimizing the sum of purchasing cost, administration cost (e.g. ordering and documentation) and transportation cost. Minimization of F1 can be expressed as follows:

$$
\begin{aligned}
& \text { Min } F 1=\sum_{i \in I} \sum_{j \in J} C_{i}^{p} q_{i j}+\sum_{j \in J} \sum_{k \in K} C_{j}^{p} q_{j k}+\sum_{i \in I} C_{i}^{a} u_{i} \\
& +\sum_{j \in J} C_{j}^{a} v_{j}+\sum_{i \in I} \sum_{j \in J} C_{i j}^{t}\left\lceil\frac{q_{i j}}{T C}\right\rceil d_{i j} \\
& +\sum_{j \in J} \sum_{k \in K} C_{j k}^{t}\left\lceil\frac{q_{j k}}{T C}\right\rceil d_{j k}
\end{aligned}
$$

\section{Minimization of environmental impact (F2)}


This objective function aims at minimizing the environmental impact in terms of $\mathrm{CO}_{2}$ emissions throughout the transportation process from farms to abattoirs and from abattoirs to retailers. Minimization of F2 can be expressed as follows:

$$
\operatorname{Min} F 2=\sum_{i \in I} \sum_{j \in J} C O_{2 i j}\left\lceil\frac{q_{i j}}{T C}\right\rceil d_{i j}+\sum_{j \in J} \sum_{k \in K} C O_{2 j k}\left\lceil\frac{q_{i j}}{T C}\right\rceil d_{j k}
$$

\section{Maximization of social impact (F3)}

This objective function aims at maximizing the social impact of suppliers (e.g. farms and abattoirs). To this aim, Suppliers' weights in social criteria obtained by Fuzzy TOPSIS are employed as a coefficient for all livestock ordered from farm $i$ to abattoir $j$ and for all meat packets ordered from abattoir $j$ to retailer $k$. Maximization of F3 can be expressed as follows:

$$
\operatorname{Max} F 3=\sum_{i \in I} \sum_{j \in J} w_{i}^{s} q_{i j}+\sum_{j \in J} \sum_{k \in K} w_{j}^{s} q_{j k}
$$

\section{Minimization of travel time (F4)}

This objective function aims at minimizing the travel time of all livestock from farms to abattoirs and of all meat packets from abattoirs to retailers. Minimization of F4 can be expressed as follows:

$$
\text { Min F4 }=\sum_{i \in I} \sum_{j \in J} \frac{d_{i j}}{V} q_{i j}+\sum_{j \in J} \sum_{k \in K} \frac{d_{j k}}{V} q_{j k}
$$

Subject to:

\section{Supply capacity constraints}

These constraints ensure that all quantity of livestock ordered from supplier $i$ and of meat packets ordered from supplier $j$ should be equal to or less than the capacity of both farms and abattoirs. These constraints for both suppliers $i$ and $j$ can be expressed as follows:

$$
\begin{aligned}
& \sum_{i \in I} q_{i j} \leq S_{i} u_{i} \quad \forall j \in J \\
& \sum_{j \in J} q_{j k} \leq S_{j} \mathrm{v}_{j} \quad \forall \mathrm{k} \in K
\end{aligned}
$$

\section{Demand constraints}

These constraints ensure that the demands of abattoir $j$ and retailer $k$ are fulfilled from supplier $i$ and supplier $j$, respectively. These constraints can be expressed as follows:

$$
\begin{array}{ll}
\sum_{i \in I} q_{i j} \geq \mathrm{D}_{j} & \forall j \in J \\
\sum_{j \in J} q_{j k} \geq D_{k} & \forall k \in K \\
\mathrm{D}_{k} \geq \sum_{k \in K} q_{j k} & \forall j \in J
\end{array}
$$

\section{Non-negativity and binary constraints}

These constraints ensure that (1) the quantity of all products throughout the meat supply chain are nonnegative; and (2) the decision variables $u_{i}$ and $v_{j}$ are binary. These constraints can be expressed as follows:

$$
\begin{gathered}
q_{i j}, q_{j k} \geq 0 \quad \forall i, j, k \\
u_{i}, v_{j} \in\{1,0\}, \forall i, j
\end{gathered}
$$

\section{B. Solution approach}

In this work, to obtain a set of Pareto solution based on the developed MOO model, the LP-metrics approach was used. Based on this approach, the aggregation formula is expressed as follows [18]:

$$
\operatorname{Min} \mathrm{F}=\left[\begin{array}{l}
w_{1} \frac{F 1-F 1^{*}}{F 1^{*}}+w_{2} \frac{F 2-F 2^{*}}{F 2^{*}} \\
+w_{3} \frac{F 3-F 3^{*}}{F 3^{*}}+w_{4} \frac{F 4-F 4^{*}}{F 4^{*}}
\end{array}\right]
$$

Subject to Eqs. 16-22.

The ideal objectives values $\left(\mathrm{F}^{*}, \mathrm{~F} 2^{*}, \mathrm{~F} 3^{*}\right.$ and $\left.\mathrm{F} 4^{*}\right)$ were obtained via the individual optimization for the four objective functions.

The global criterion method was used for supporting decision makers in determining the final solution. This solution selects the final solution that reveals the shortest distance to the ideal solution $\left(F_{n}^{*}\right)$ [19]. The decisionmaking formula is expressed as follows:

$$
\text { Min } \mathrm{md}=\left(\sum_{n=1}^{4}\left|F_{n}-F_{n}^{*}\right|^{\rho}\right)^{1 / \rho} ; 1 \leq \rho \leq \infty
$$

The solution that reveals a minimum distance (md) is selected as a final solution. Generally, $\rho$ is 1 ; However, other values of $\rho$ also can be used.

\section{A CASE STUDY}

Considering sustainability in evaluating and selecting suppliers represents one of the most important concerns in sustainable supply chain management. The case under study considers a supplier selection and order allocation problem in a meat supply chain in selecting the sustainable suppliers of livestock and meat packets. Table III shows the input parameters utilized for applying the case study. Parameters which are related to locations, demand and capacity of farms, abattoirs and retailers, were collected from the Meat Committee in the UK [20]. Transportation distances among livestock and meat packets suppliers and retailers were estimated using Google Map. The MOO problem was solved via LINGO ${ }^{11}$ software running on a personal computer with a Corei5 $2.7 \mathrm{GHz}$ processor and with $8 \mathrm{~GB}$ RAM.

The developed fuzzy TOPSIS-MOO approach was applied as follows:

Step 1: To better define the criteria used for evaluating livestock and meat packets suppliers, 10 criteria in three dimensions were identified based on traditional, environmental and social aspects, as illustrated in Fig. 1. As shown in Fig. 1 there are four traditional criteria, three green criteria and three social criteria.

Step 2: Fuzzy TOPSIS was applied for evaluating criteria and suppliers with respect to each criterion. The evaluation for both stages (e.g. livestock and meat packets suppliers) were based on the traditional $(\mathrm{t})$, green (g) and social (s) criteria.

Step 2.1: The evaluation of criteria and suppliers were performed by two decision makers from an abattoir $\left(D_{a 1}\right.$ and $\left.D_{a 2}\right)$ for evaluating three livestock suppliers $\left(S_{11}, S_{12}\right.$, $\left.\mathrm{S}_{13}\right)$ and two decision makers from two retailers $\left(D_{\mathrm{r} 1}\right.$ and $\left.D_{\mathrm{r} 2}\right)$ for evaluating three meat packets suppliers $\left(\mathrm{S}_{\mathrm{m} 1}, \mathrm{~S}_{\mathrm{m} 2}\right.$, $\left.\mathrm{S}_{\mathrm{m} 3}\right)$. 
Step 2.2: Linguistic terms that were used for evaluating the three sets of criteria and suppliers were re-represented into triangular fuzzy numbers. Tables IV and V show (1) the obtained evaluation of criteria and livestock suppliers based on the evaluation of $D_{a 1}$ and $D_{a 2}$ and (2) the obtained evaluation of criteria and meat packets suppliers based on the evaluation of $\mathrm{D}_{\mathrm{r} 1}$ and $\mathrm{D}_{\mathrm{r} 2}$, respectively.

Step 2.5: The distance of each supplier from the positive ideal solution $\left(D_{i}^{+}\right)$and the negative ideal solution $\left(D_{i}^{-}\right)$ are calculated. The closeness coefficient (CC) for each supplier is determined based the obtained distances.

TABLE III. DATA FOR THE CASE STUDY

\begin{tabular}{cccc}
\hline $\mathrm{I}=3$ & $C_{i}^{t}=1-1.5$ & $d_{j k}=110$, & $D_{j}=1250,1450$ \\
& & 174 & \\
$\mathrm{~J}=3$ & $C_{j k}^{t}=1-1.5$ & $T C=80$ & $D_{k}=1100,1300$ \\
$\mathrm{~K}=5$ & $C_{i}^{a}=3-4.5$ & $V=90-110$ & $C O_{2 i j}=271,294$ \\
& $C_{j}^{a}=3-4.5$ & $S_{i}=1500$, & $C_{2 j k}=271,294$ \\
$C_{i}^{p}=130-$ & 1800 \\
150 & & \\
$\mathrm{C}_{\mathrm{i}}^{r}=155-$ & $d_{i j}=43,210$ & $S_{j}=1600$, \\
175 & & 2000 & \\
\hline
\end{tabular}

TABLE IV. EVALAUTION OF LIVESTOCK SUPPLIERS AND CRITERIA BASED ON $D_{A 1}$ AND D $D_{A 2}$

\begin{tabular}{ccccc}
\hline $\begin{array}{c}\text { Sub- } \\
\text { criteria }\end{array}$ & Weight & $\mathbf{S}_{\mathbf{l 1}}$ & $\mathbf{S}_{\mathbf{l} 2}$ & $\mathbf{S}_{\mathbf{1 3}}$ \\
\hline $\mathrm{t} 1$ & $(0.8,0.9,1)$ & $(7,8,9)$ & $(9,10,10)$ & $(7,7,8)$ \\
$\mathrm{t} 2$ & $(0.9,1,1)$ & $(7,8,9)$ & $(9,10,10)$ & $(7,8,9)$ \\
$\mathrm{t} 3$ & $(0.5,0.6,0.7)$ & $(6,7,8)$ & $(7,9,9)$ & $(7,8,9)$ \\
$\mathrm{t} 4$ & $(0.8,0.9,1)$ & $(6,7,8)$ & $(7,8,9)$ & $(7,8,9)$ \\
$\mathrm{g} 1$ & $(0.9,0.9,1)$ & $(7,8,9)$ & $(7,8,9)$ & $(7,8,9)$ \\
$\mathrm{g} 2$ & $(0.7,0.8,1)$ & $(6,7,8)$ & $(8,8,9)$ & $(8,8,9)$ \\
$\mathrm{g} 3$ & $(0.6,0.7,0.8)$ & $(6,7,8)$ & $(7,7,8)$ & $(7,7,8)$ \\
$\mathrm{s} 1$ & $(0.6,0.7,0.8)$ & $(7,8,9)$ & $(9,10,10)$ & $(7,7,8)$ \\
$\mathrm{s} 2$ & $(0.5,0.6,0.7)$ & $(9,10,10)$ & $(8,8,9)$ & $(6,7,8)$ \\
$\mathrm{s} 3$ & $(0.9,1,1)$ & $(6,7,8)$ & $(9,10,10)$ & $(7,8,9)$ \\
\hline
\end{tabular}

TABLE VIII. THE OPTIMAL SUSTAINABLE ORFER ALLOCATION

\begin{tabular}{ccccccccc}
\hline Supplier & Abattoir & Abattoir & Abattoir & Retailer & Retailer & Retailer & Retailer & Retailer \\
& $\mathbf{1}$ & $\mathbf{2}$ & $\mathbf{3}$ & $\mathbf{1}$ & $\mathbf{2}$ & $\mathbf{3}$ & $\mathbf{4}$ & $\mathbf{5}$ \\
\hline $\mathrm{S}_{11}$ & 205 & 111 & 203 & - & - & - & - & - \\
$\mathrm{S}_{\mathrm{l} 2}$ & 275 & 170 & 80 & - & - & - & - & - \\
$\mathrm{S}_{\mathrm{S}}$ & 188 & 211 & - & - & - & - & - & - \\
$\mathrm{S}_{\mathrm{m} 1}$ & - & - & - & 128 & 147 & 134 & 141 & 131 \\
$\mathrm{~S}_{\mathrm{m} 2}$ & - & - & - & 115 & 42 & - & 110 & - \\
$\mathrm{S}_{\mathrm{m} 3}$ & - & - & - & - & 106 & 130 & 144 & 150 \\
\hline
\end{tabular}

TABLE V. EVALAUTION OF MEAT PACKETS SUPPLIERS AND CRITERIA BASED ON D $D_{\mathrm{R} 1}$ AND $\mathrm{D}_{\mathrm{R} 2}$

\begin{tabular}{ccccc}
\hline $\begin{array}{c}\text { Sub- } \\
\text { criteria }\end{array}$ & Weight & $\mathbf{S}_{\mathbf{m} 1}$ & $\mathbf{S}_{\mathbf{m} 2}$ & $\mathbf{S}_{\mathbf{m} 3}$ \\
\hline t1 & $(0.9,1,1)$ & $(9,10,10)$ & $(5,7,6)$ & $(7,7,8)$ \\
t2 & $(0.8,0.9,1)$ & $(7,7,8)$ & $(6,7,7)$ & $(6,7,7)$ \\
t3 & $(0.8,0.9,1)$ & $(7,8,8)$ & $(3,4,4)$ & $(7,8,8)$ \\
t4 & $(0.6,0.7,0.8)$ & $(7,7,8)$ & $(7,7,8)$ & $(6,7,7)$ \\
g1 & $(0.8,0.9,1)$ & $(6,7,8)$ & $(3,3,4)$ & $(6,6,7)$ \\
g2 & $(0.5,0.6,0.6)$ & $(7,8,8)$ & $(6,6,7)$ & $(9,10,10)$ \\
g3 & $(0.5,0.6,0.6)$ & $(5,6,6)$ & $(3,3,4)$ & $(7,7,8)$ \\
s1 & $(0.7,0.8,0.8)$ & $(9,10,10)$ & $(7,8,8)$ & $(7,8,8)$ \\
s2 & $(0.7,0.8,0.8)$ & $(7,8,9)$ & $(1,2,2)$ & $(7,8,8)$ \\
s3 & $(0.8,0.9,1)$ & $(9,9,10)$ & $(3,4,4)$ & $(9,10,10)$ \\
\hline
\end{tabular}

TABLE VI. CLOSENESS COEFFICIENT AND DISTANCES FROM THE POSITIVE IDEAL/NEGATIVE IDEAL SOLUTIONS RELATED TO ALL SUPPLIERS

\begin{tabular}{cccc}
\hline & Sl1 & Sl2 & S13 \\
\hline$D_{i}^{+}$ & 1.327 & 0.756 & 1.083 \\
$D_{i}^{-}$ & 5.988 & 6.921 & 6.345 \\
$\mathbf{C C}$ & 0.818 & 0.901 & 0.854 \\
rank & 3 & 1 & 2 \\
\hline & Sm1 & Sm2 & Sm3 \\
\hline$D_{i}^{+}$ & 0.818 & 1.381 & 0.972 \\
$D_{i}^{-}$ & 5.556 & 6.509 & 5.990 \\
$\mathbf{C C}$ & 0.871 & 0.824 & 0.860 \\
rank & 1 & 3 & 2 \\
\hline
\end{tabular}

Table VI shows the obtained results of livestock and meat packets suppliers. Based on the obtained results, the ranking of the three livestock suppliers is given as $\mathrm{LS} 2>\mathrm{LS} 3>\mathrm{LS} 1$ and is given as MS1>MS3 $>$ MS2 for the three meat packets suppliers. Subsequently, the results, revealed that livestock supplier two and meat packets supplier one are the best sustainable supplier.

Step 3: The multi-objective model was optimized using the LP-metrics approach to allocate the optimal order allocation for each livestock and meat packets suppliers and to obtain trade-offs (a set Pareto solutions) among the four objectives.

Step 3.1: The minimum and maximum values for the four objectives were determined using the individual optimization. The results are $(\{\operatorname{Min}, \operatorname{Max}\})=(\{334,438$, $489,520\},\{450814.39,739901.27\},\{1360.5,1730\}$, $\{43.1,203.7\})$. Subsequently, the ideal solutions $\left(\mathrm{F}^{*}, \mathrm{~F}^{*}{ }^{*}, \mathrm{~F}^{*}\right.$ and $\left.\mathrm{F} 4^{*}\right)$ are: $F 1^{*}=334,438, F 2^{*}=$ $450814.39, F 3^{*}=1730$ and $F 4^{*}=43.1$.

Step 3.2: The multi-objective model was optimized using the LP-metrics approach based on the results obtained in Step 3.1 and 10 different combinations of weights. Table VII shows the obtained Pareto solutions.

Step 5: Each of the obtained Pareto solution leads to a different order allocation with respect to a trade-off 
among the four objectives. Thus, decision makers need to select one solution to allocate their orders from each supplier. To this aim, the global criterion approach was applied to select the final solution that leads to the minimum distance to its ideal solution. Accordingly, solution number 5 revealed the lowest value; thus, it is selected as the final solution since it led to the minimum distance to the ideal solutions ( $\mathrm{md}=0.608$ ). Based on solution number 5, Table VIII shows the optimal quantity of livestock and meat packets that should be ordered from livestock and meat packets suppliers, respectively.

\section{CONCLUSION}

This research presents a development of an integrated approach to solve a sustainable two-stage supplier selection and order allocation problem for a meat supply chain considering traditional, environmental and social criteria. The developed approach can be concluded in five steps: sub-criteria for traditional, environmental and social criteria were identified in the first step. In the second step, fuzzy TOPSIS was used for ranking the suppliers based on the identified sub-criteria. In the third step, a multiobjective optimization model was developed for obtaining the optimal solutions of order allocation in quantity. The objectives are minimizing the expected costs of transportation, purchasing and administration, the environmental impact (particularly, $\mathrm{CO}_{2}$ emissions) and the travel time of products and maximizing the social impact. In the fourth step, LP-metrics approach was used to reveal a set of Pareto solutions based on the developed multi-objective optimization model and the final solution was determined by using the global criterion approach in the fifth step. The obtained sustainable supplier selection and order allocation shows that the developed fuzzy TOPSIS-multi-objective approach can be used as a reference for supply chain managers in evaluating the sustainable performance of the potential suppliers and ordering the optimal quantity of products from each supplier with respect to a trade-off among conflicting objectives.

\section{References}

[1] M.S. Lee, S.R. Jin, C. Donghyun, and N. Yonghwi, "Pressures affecting green supply chain performance," Management Decision, vol.51, pp.1753-1768, 2013.

[2] F.E. Boran, S. Genç, M. Kurt, and D. Akay, "A multi-criteria intuitionistic fuzzy group decision making for supplier selection with TOPSIS method,“ Expert Syst. Appl. vol.36, pp.11363$11368,2009$.

[3] A. Amid, S.H. Ghodsypour, and C. O'Brien, "Fuzzy multiobjective linear model for supplier selection in a supply chain,“'Int. J. Prod. Econ. vol.104, pp.394- 407, 2006.
[4] M. Yazdani, S. Hashemkhani Zolfani, and E.K. Zavadskas, "New integration of MCDM methods and QFD in the selection of green suppliers,“J. Bus. Econ. Manag. pp.1-17, 2016.

[5] N. Claudia, R. Lasch, and R. Kellner, "Integrating sustainability into strategic supplier portfolio selection," Management Decision, vol.54, 194-221, 2016.

[6] A. Fallahpour, E.U. Olugu, S.N. Musa, K.Y. Wong, and S. Noori, "A decision support model for sustainable supplier selection in sustainable supply chain management," Computers \& Industrial Engineering vol.105, pp.391-410, 2017.

[7] A. Mohammed, and Q. Wang, "Developing a meat supply chain network design using a multi-objective possibilistic programming approach," British Food Journal, volo.119, pp.690-706, 2017.

[8] E. Bottani, and A. Rizzi, "A fuzzy multi-attribute framework for supplier selection in an e-procurement environment," International Journal of Logistics Research and Applications, vol.8, pp.249266, 2005.

[9] C.T. Chen, C. T. Lin, and S. F. Huang, "A fuzzy approach for supplier evaluation and selection in supply chain management," International Journal of Production Economics, vol.102, pp.289$301,2006$.

[10] J. Roshandel, S.S. Miri-Nargesi, and L. Hatami-Shirkouhi, "Evaluating and selecting the supplier in detergent production industry using hierarchical fuzzy TOPSIS," Applied Mathematical Modelling, vol.37, pp.10170-10181, 2013.

[11] F.R.L. Junior, L. Osiro, and L.C.R. Carpinetti, "A comparison between Fuzzy AHP and Fuzzy TOPSIS methods to supplier selection," Applied Soft Computing, vol.21, pp.194-209, 2014.

[12] J. Dai, and J. Blackhurst. "A Four-phase AHP-QFD Approach for Supplier Assessment: A Sustainability Perspective,” Int. J. Prod. Resh., vol.50, pp.5474-5490, 2011.

[13] G. Akman, "Evaluating suppliers to include green supplier development programs via fuzzy c-means and VIKOR methods," Comput. Ind. Eng., vol.86, pp.69-82, 2015.

[14] C.W. Hsu, T.C. Kuo, S.H. Chen, and A.H. Hu, "Using DEMATEL to develop a carbon management model of supplier selection in green supply chain management,“ J. Clean. Prod., vol.56, pp.164-172, 2013.

[15] K. Govindan, M. Kadziński, and R. Sivakumar, "Application of a novel PROMETHEE-based method for construction of a group compromise ranking to prioritization of green suppliers in food supply chain," Omega, vol.71, pp.129-145, 2017.

[16] E. Çevikcan, S. Çebi, and I. Kaya, "Fuzzy VIKOR and fuzzy axiomatic design versus to fuzzy TOPSIS: an application of candidate assessment," J. Multi-Valued Log S., vol.15, pp.181208, 2009.

[17] H.C.W. Lau, C.W.Y. Wong, P.K.H. Lau, K.F. Pun, K.S. Chin, and B. Jiang, "A fuzzy multi- criteria decision support procedure for enhancing information delivery in extended enterprise networks," Eng. App. Art. Int., vol.16, pp.1-9, 2003.

[18] A. Mohammed, and Wang, Q. "The fuzzy multi-objective distribution planner for a green meat supply chain," Int. J. Pro. Eco., vol.184, pp.47-58, 2017.

[19] A. Mohammed, and Wang, Q. "Multi-criteria optimization for a cost-effective design of an RFID-based meat supply chain," British Food Journal, vol.119, pp.676-689, 2017.

[20] HMC, UK. (2010). http://www.halalhmc.org/ , Available: http://www.halalhmc.org/test-demo.htm . (accessed October 26, 2016). 